\title{
FIELD MEASUREMENT OF POHANG NEW HARBOR FOR INVESTIGATING DOWNTIME FACTORS
}

\author{
Moonsu Kwak ${ }^{1}$, Wonmu Jeong ${ }^{2}$, Kyongho Ryu ${ }^{3}$ and Chongkun Pyun ${ }^{4}$
}

This study is investigated a cause induced downtime through the field measurement and the downtime monitoring system in Pohang new harbor. The downtime events arose eleven times during November 11, 2008 to February 4, 2009. The causes induced downtime understood as swell at seven times, wave with strong wind at two times, swell with strong wind at one time and waves at one time. We can understand that swell affected in major cause induced downtime of 1,500 GT 23,000 GT size ships in Pohang new harbor.

\section{Keywords: downtime factor; field measurement; Pohang New Harbor \\ INTRODUCTION}

Pohang new harbor situated in the Yongil bay in the southeast of Korea, is the largest industrial harbor in Korea and is one of the largest industrial harbors in the world. The harbor handles cargos of steel company POSCO and other industrial complex in the region. The pier structure and the loading and unloading facilities are capable of handling 36 ships concurrently which handle 47 million tons yearly including 250,000DWT size ship. Due to its location and the coastline orientation, Pohang new harbor has been found to provide a fairly good protection against typhoons coming from the south.

However, downtime of loading and unloading activities of the ship has occurred frequently, which decreased effective working day. It is shown that the two major causes of downtime are the wind wave higher than loading criteria and the swell with longer period more than $10 \mathrm{sec}$ according to the previous study (Jeong et al. 1997; Kwak et al. 2008). Pohang new harbor has shown a downtime on the pier $7^{\text {th }}$ and $8^{\text {th }}$, where are located in near entrance to harbor at present. Therefore the harbor is in need to improve on the harbor tranquility so that downtimes at these piers decrease. This paper presents results of a field measurement for exploring the causes of downtime in Pohang New Harbor.

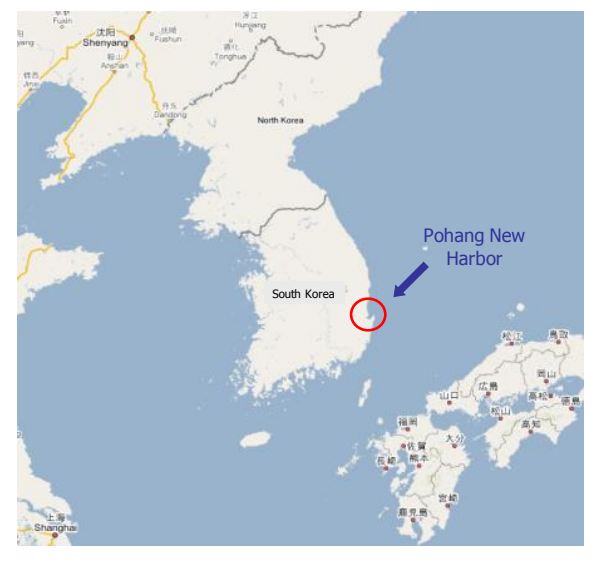

Figure 1. Location map of the Pohang New harbor.

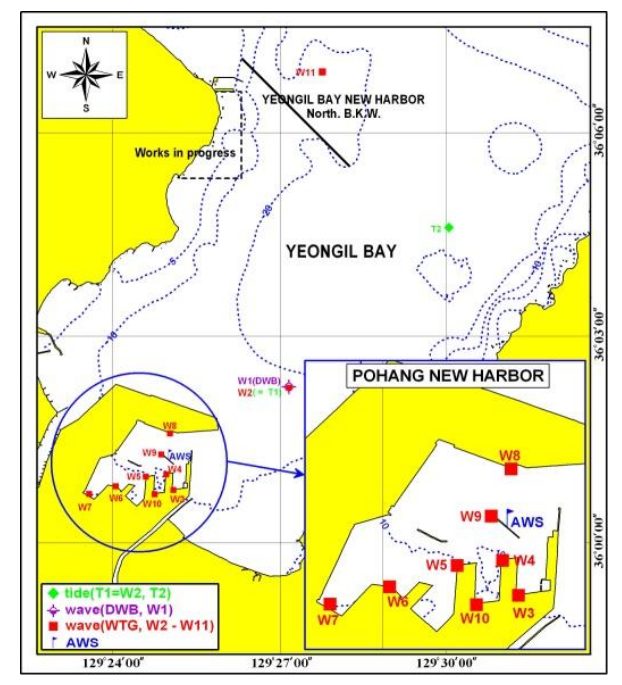

Figure 2. Location map of the measurement stations.

\footnotetext{
1 Ph.D., Professor of Civil Engineering, Myongji College, Gajaro 134, Seodaemun, Seoul 120-776, Korea (moonsu@mjc.ac.kr)

2 Ph. D., Seniority Researcher of Coastal Engineering Division, Korea Ocean Research and Development Institute, Ansan P.O. Box 29, Kyonggi 425-600, Korea (wmjeong@kordi.re.kr)

${ }^{3}$ Researcher of Coastal Engineering Division, Korea Ocean Research and Development Institute, Ansan P.O. Box 29, Kyonggi 425-600, Korea (ryukh75@kordi.re.kr)

${ }^{4}$ Ph. D., Professor of Civil and Environmental Engineering, Myongji University, Namdong, Yongin, Kyonggi 449-728, Korea (ckpyun@mju.ac.kr)
} 


\section{FIELD MEASUREMENT DATA}

Figure 1 presents the location map of the Pohang new harbor(left) and the measurement stations(right). The wave heights were measured at ten stations, which used the directional wave rider buoy at W1 outside harbor and pressure type wave gauge at W2 to W10 inside harbor for 12 months. The tide was measured at two stations T1 and T2 outside harbor, where the tide gauge was used. The weather was observed at one station AWS inside harbor.

The left side of Figure 2 presents the wave height (solid line), wave direction (dot) and wave period (dashed line) at station W1 outside harbor for one month. The left side ordinate is the wave height and wave direction, and the right side ordinate is the wave period. The abscissa is the date from 1 to 30 November 2008. Two high wave heights are clearly seen in this figure. These heights show on November 8 and 29 which measured $2.2 \mathrm{~m}, 13.0 \mathrm{sec}$ and $2.0 \mathrm{~m}, 10.0 \mathrm{sec}$ at NNE direction. The right side of Figure 2 presents the wave height (solid line) and wave period (dashed line) at station W4 in the pier $8^{\text {th }}$ covering the same date range. It is also noted that two high wave heights also exist on November 8 and 29 which measured $0.65 \mathrm{~m}, 13.0 \mathrm{sec}$ and $0.5 \mathrm{~m}, 10.0 \mathrm{sec}$.

And then, we are carrying out the field monitoring system for recording downtime at the $3^{\text {rd }}$ to $8^{\text {th }}$ Piers. As a consequence of field monitoring, we could see that downtime actually occurred when wave height measured over $2.0 \mathrm{~m}$ at station $\mathrm{W} 1$.
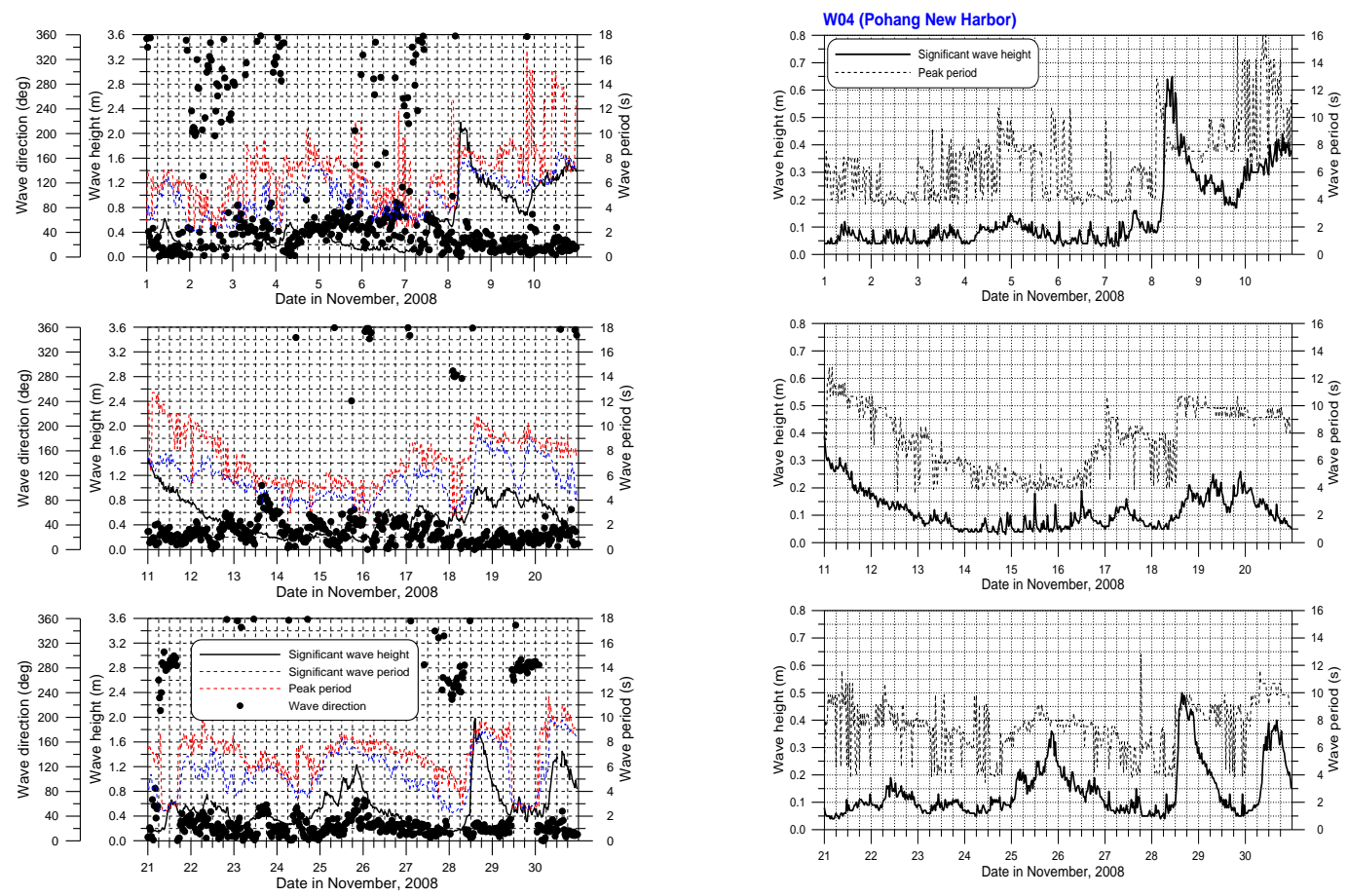

Figure 3. Results of the field data at Station W1(left) and W4(right) on November 2008.

\section{INVESTIGATION OF DOWNTIME FACTOR}

An investigation of cause induced downtime has done for November 1, 2008 to February 42009 when we were carrying out the field monitoring system for recording downtimes. During that time, the downtime events arose at eleven times as Table 1, that they come from swell at seven times, waves with strong wind at two times, swell with strong wind at one time and wind waves at one time.

The first downtime event after starting the monitoring system comes from wind waves with strong wind at $42^{\text {nd }}$ berth on November 8 9, 2008. The cargo ship, which has the 1,592 GT size, had downtime for nine hours at that time. The left side in Figure 3 shows the measurement data at station $\mathrm{W} 1 \sim \mathrm{W} 10$ between $8^{\text {th }}$ and $12^{\text {th }}$ November 2008. The measurement data at station $\mathrm{W} 1$ shows the 2.0 2.2 $\mathrm{m}$ wave height, $8.0 \mathrm{sec}$ wave period and $9.0 \sim 12.0 \mathrm{~m} / \mathrm{sec}$ wind speed at NE ENE direction. The left side 
of Figure 4 shows the normalized directional energy density spectrum of the measurement data, which measured on these days. The wave energy has the largest value when the wave period is $8.0 \mathrm{sec}$ and the wave direction is NE.

The other downtime events which come from swell appeared to twelve berths of five piers $\left(3^{\text {rd }}, 4^{\text {th }}, 5^{\text {th }}\right.$ $7^{\text {th }}$ and $8^{\text {th }}$ ) between $28^{\text {th }}$ and $29^{\text {th }}$ November 2008. The sizes of ship with induced downtime varied from $1,593 \mathrm{GT}$ to $22,817 \mathrm{GT}$, and downtime duration was fifteen hours. The right side of Figure 3 shows the measurement data at station $\mathrm{W} 1 \sim \mathrm{W} 10$ between $28^{\text {th }}$ November and $2^{\text {nd }}$ December 2008 . The measurement data at station $\mathrm{W} 1$ were between 1.6 and $2.2 \mathrm{~m}$ in wave heights, $9.0 \mathrm{sec}$ wave period with NNE NE wave direction. The normalized directional energy density spectrum is shown in the right side of Figure 4. The largest value of wave energy was when the wave period was $10.0 \mathrm{sec}$ and the wave direction was NNE NE.

Table 1. List of the downtime events at November 2008 to February 2009.

\begin{tabular}{|c|c|c|c|c|}
\hline \multirow{2}{*}{ Event } & Duration & \multirow{2}{*}{$\begin{array}{c}\text { Occurrence } \\
\text { berth }\end{array}$} & \multicolumn{2}{|c|}{ Downtime factor } \\
\cline { 4 - 5 } & & First stage & Continuance \\
\hline \hline 1 & $' 0811 / 0810 \mathrm{H}^{\sim} 11 / 0907 \mathrm{H}$ & 4 & wind+waves & waves \\
\hline 2 & $' 0811 / 0920 \mathrm{H}^{\sim} 11 / 1113 \mathrm{H}$ & $3,4,5,7,8$ & waves & waves+swell \\
\hline 3 & $' 0811 / 2816 \mathrm{H}^{\sim} 11 / 2910 \mathrm{H}$ & $3,4,5,7,8$ & swell & swell \\
\hline 4 & $' 0811 / 3016 \mathrm{H}^{\sim} 12 / 0107 \mathrm{H}$ & 7 & swell & swell \\
\hline 5 & $' 0812 / 1401 \mathrm{H}^{\sim} 12 / 1507 \mathrm{H}$ & $2,4,7,8$ & swell & swell \\
\hline 6 & $' 0812 / 1821 \mathrm{H}^{\sim} 12 / 2007 \mathrm{H}$ & $3,4,5,7,8$ & swell & swell \\
\hline 7 & $' 0812 / 2119 \mathrm{H}^{\sim} 12 / 2307 \mathrm{H}$ & $2,4,5,7,8$ & swell & swell \\
\hline 8 & $' 0812 / 2813 \mathrm{H}^{\sim} 12 / 2907 \mathrm{H}$ & 7,8 & swell & swell \\
\hline 9 & $' 0812 / 3108 \mathrm{H}^{\sim}$ '091/4 18H & $2,3,4,5,7,8$ & swell & swell \\
\hline 10 & $' 0901 / 0918 \mathrm{H}^{\sim} 01 / 1512 \mathrm{H}$ & $1,2,3,4,5,6$, & wind+ swell & swell \\
\hline 11 & $' 0901 / 3008 \mathrm{H}^{\sim} 02 / 0207 \mathrm{H}$ & $2,3,4,5,6,7,8$ & wind+waves & swell \\
\hline
\end{tabular}
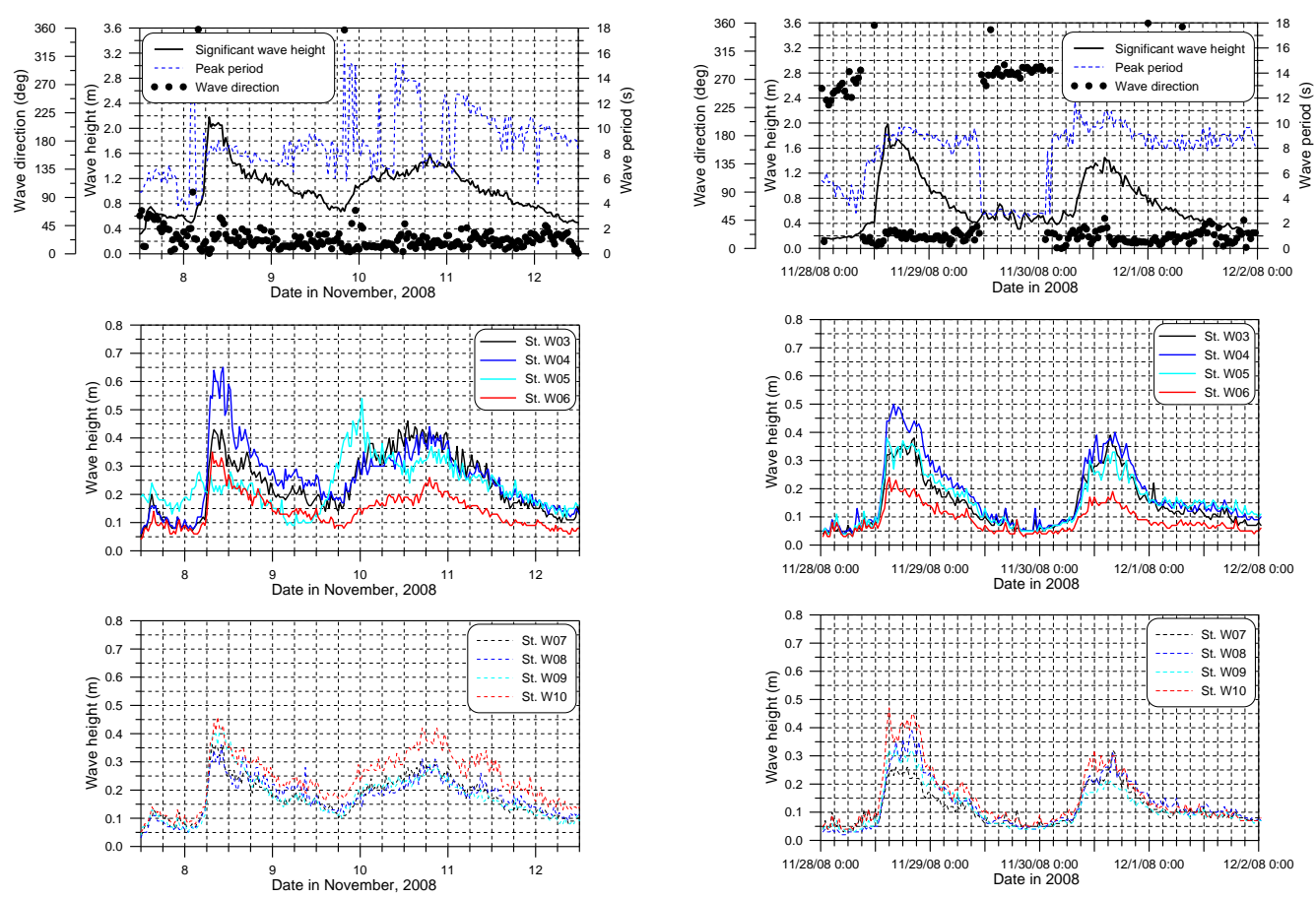

Figure 4. Results of field data at November 2008 (left), and December 2009 (right). 

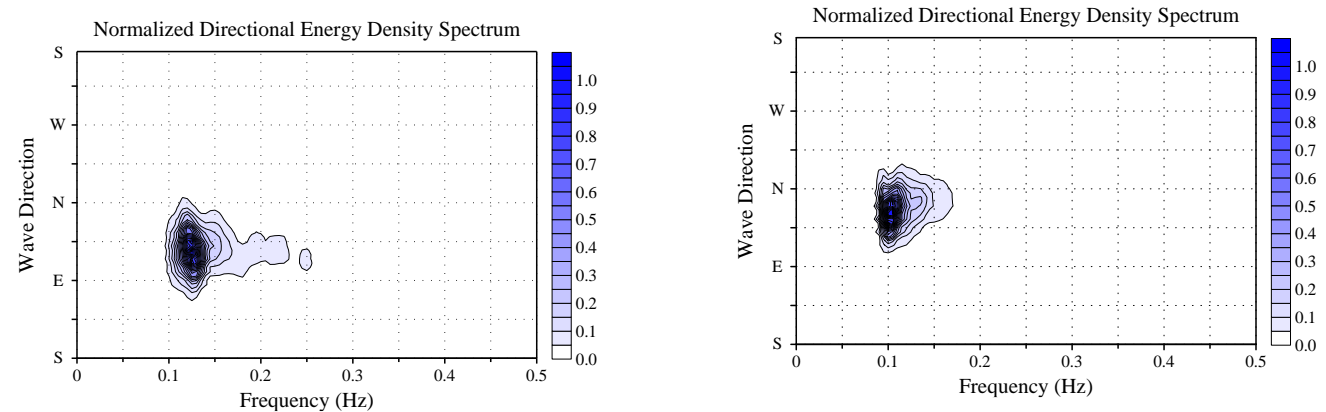

Figure 5. Normalized directional energy density spectrum at November 2008(left), and December 2008(right).

\section{CONCLUSIONS}

The purpose of this study was to investigate causes of induced downtime through the field measurements and the downtime monitoring system in Pohang new harbor. The downtime events arose eleven times between $11^{\text {th }}$ November 2008 and $4^{\text {th }}$ February 2009. The causes of induced downtime are understood to be swells at seven times, waves with strong wind at two times, a swell with strong wind at one time and waves at one time on the first stage, but the causes of induced downtime on continuance stage were swells at nine times and waves at two times. However, it is possible to conclude that the swell is the major cause of induced downtime of 1,500 GT 23,000 GT size ships in Pohang new harbor.

\section{REFERENCES}

Jeong W.M., S.B. Oh, J.W. Chae and S.I. Kim. 1997. Analysis of the wave induced downtime at Pohang new harbor, J. of Korean Society of Coastal and Ocean Engineers, 9(1), pp.24-34.

Kwak M., W. Jeong, C. Pyun, X. Xing and J.J. Lee. 2008. Computer simulation of Pohang new harbor for seiche reduction, Proceedings of the $31^{\text {th }}$ International Conference Coastal Engineering, ASCE, 3996-4001. 